ISSN: 2224-0616

Int. J . Agril. Res. Innov. \& Tech. 7 (1): 38-42, J une, 2017

Available online at http://www.ijarit.webs.com

\title{
POSSIBILITY OF RECOVERING FUSARIUM WILT AFFECTED EGGPLANTS BY TRICHODERMA
}

\author{
M.C. Adhikary, H.A. Begum and M.B. Meah*
}

Received 7 March 2017, Revised 21 May 2017, Accepted 26 June 2017, Published online 30 June 2017

\begin{abstract}
The efficacy of Trichoderma suspension on the recovery of fusarium wilt infected eggplant was studied at Bangladesh Agricultural University Farm during J uly 2014 to April 2015. Suspension of Trichoderma asperellum CP (IPM 33) $\left(5.8 \times 10^{7} \mathrm{CFU} \mathrm{ml}^{-1}\right)$ was applied to rhizosphere soils of eggplants @ 0, 20 and $40 \mathrm{ml}^{\text {plant }}{ }^{-1}$. Fusarium oxysporum f. sp. melongenae was inoculated to flowering and fruiting stages of healthy plants by soil drenching method $48 \mathrm{hrs}$ before and after application of Trichoderma suspension. Observations were made on the severity and recovering of wilting. The eggplant variety BAU Begun 1 was found resistant to fusarium wilt while other two varieties BAU Begun 2 and Dohazari G showed susceptible reaction. Pre-inoculation application of Trichoderma @ $40 \mathrm{ml}^{\text {plant }}{ }^{-1}$ significantly reduced the severity of the disease. The vulnerability to fusarium wilt was higher at flowering stage of eggplant. Thus, the experimental results have opened up a possibility of using Trichoderma suspension over conventional farming inputs for sustainable and organic production of eggplant.
\end{abstract}

Keywords: Fusarium Wilting, Trichoderma, Infection Recovery

IPM Lab, Department of Plant Pathology, Bangladesh Agricultural University, Mymensingh 2202, Bangladesh

*Corresponding author's email: bmeah@yahoo.com (M.B. Meah)

\section{Introduction}

Among the vegetables grown in Bangladesh, eggplant (Solanum melongena L.) is most important in terms of round the year availability, food value, taste, farmer's income perspective and as an export item. In a subtropical country like Bangladesh, eggplant is grown all over the country on medium high land to high land in both Rabi and Kharif seasons. It is positioned the $2^{\text {nd }}$ in acreage, production, yield, and in consumption next to potato. In the year 2014-15, total 76370 acres land were under eggplant cultivation, total production was 310,354 MT and yield was $4 \mathrm{t} \mathrm{ha}^{-1}$ (BBS, 2016).

Comparing with production and yield rate in other countries, the position of Bangladesh is very poor for the lack of appropriate knowledge of sound eggplant production, 20 and 30 tons ha-1, respectively in India and Japan. The most devastating disruption in sound eggplant production, usually farmers suffer, is the management of fusarium wilt caused by Fusarium oxysporum f. sp. melongenae. Some $20-30 \%$ killing of eggplant in general due to fusarium wilting is a regular report from the farmers (Begum, 2007); it may turn into epidemic causing complete failure of the crop during November to December (Meah, 1997). The fungus chokes the vascular system of plant and plant dies from water and nutritional deficiency, the fungus attacks mainly when the plants have grown up (Agrios, 2006).
Trichoderma, a common and very important soilborne fungus, has gained considerable recognition as biological agent against various soil-borne plant pathogenic fungi such as Fusarium, Sclerotium, Rhizoctonia etc. (AlChaabi and Matrod, 2002). Trichoderma produces chemicals called trichodermin, which is responsible for its antagonistic properties (Tverdyukov et al., 1994). Presence of Trichoderma, an antimicrobial bio-agent, in the soil is an indicative of the population status of plant pathogenic fungi. Its dominance indicates a pathogen-suppressive soil means a better crop growth (Elad et al., 1986; Papavizas and Lewis, 1981; Liu and Baker, 1980; Wells et al., 1972). Farmers use chemical fungicides for controlling wilting in eggplants. As a result, soil pollution arises; heavy indiscriminate use of chemical fungicides causes interference to the holistic plant health management strategies as well as to the environment and living being. So, there is a need for easy, economically feasible, eco-friendly and organically formulated biopesticide. As an alternative, IPM Lab biopesticide, an organic formulation of Trichoderma could replace or minimize the use of chemical fungicide for controlling wilting in eggplant. It is expected that application of Trichoderma suspension to control wilting in eggplant, the growth of the plant could be enhanced and crop environment becomes safe, eco-friendly and non-hazardous to the eggplant growers. The present work was undertaken to determine the efficacy of Trichoderma suspension in recovering fusarium wilt affected eggplants. 


\section{Materials and Methods}

The laboratory experiments were conducted in the Plant Disease Diagnostic Clinic (PDDC) and IPM Lab, Bangladesh Agricultural University (BAU), Mymensingh. The field experiment was conducted in the Field Laboratory of the Department of Plant Pathology, Bangladesh Agricultural University (BAU), Mymensingh during the period of July 2014- April 2015. The experiment was designed in a Randomized Complete Block Design (RCBD) with three replications. Seeds of the three eggplant varieties, viz. (1) BAU Begun 1 (2) BAU Begun 2 and (3) Dohazari G were obtained from IPM Lab, Department of Plant Pathology, BAU, Mymensingh. The isolation of F. oxysporum f. sp. melongenae was done by following tissue planting method as described by Ashrafuzzaman (1976). Culturing F. oxysporum f. sp. melongenae and Trichoderma asperellum CP (IPM 33) and preparation of spore suspension were done following the procedure of Ullah (2010). Whole field was inoculated at the flowering stage and again at the fruiting stage following the application of Trichoderma suspension to $50 \%$ of plants plot $^{-1}$ at first and then just $48 \mathrm{hrs}$ after inoculation of $F$. oxysporum $f$. sp. melongenae was done by soil drenching method and viceversa. The treatments $(\mathrm{T} 1=20$ and $\mathrm{T} 2=40 \mathrm{ml}$ plant ${ }^{-1}$ ) were applied either before pathogen inoculation i.e. pre-inoculation or after pathogen inoculation i.e. post-inoculation time. At the flowering and fruiting stages, observations were made on the number of wilting of lower leaves plant ${ }^{-1}$, number of slightly drooping of leaves plant $^{-1}$, number of wilting of all leaves except terminal buds plant ${ }^{-1}$ and number of leaves regenerated plant ${ }^{-1}$. The records on expression of symptoms on leaves were taken after inoculation at an interval of 3 days up to 21 days. Infection was expressed in percentage. To calculate the percent leaf wilted/disease incidence, total number of leaves plant ${ }^{-1}$ and number of leaves wilted plant ${ }^{-1}$ were counted. The disease severity was computed by adopting (0-4) scale for F. oxysporum f. sp. melongenae followed by Kapoor (1987).

\section{Results and Discussion}

\section{Collection and Isolation of F. oxysporum f. sp. melongenae}

Inocula of the wilted plants of eggplant collected from the Field Laboratory of the Department of Plant Pathology, Bangladesh Agricultural University (BAU), when planted on PDA grew out slowly. It was transferred, sub-cultured and purified. On PDA, the fungus grew slowly and with time produced pink pigmentation (Photograph 1). Microscopic slides were prepared and presence of macro- and micro-conidia was observed. Based on available literatures, the fungus was identified as Fusarium oxysporum $\mathrm{f}$. sp. melongenae (Brooks, 1991; Agrios, 2006).
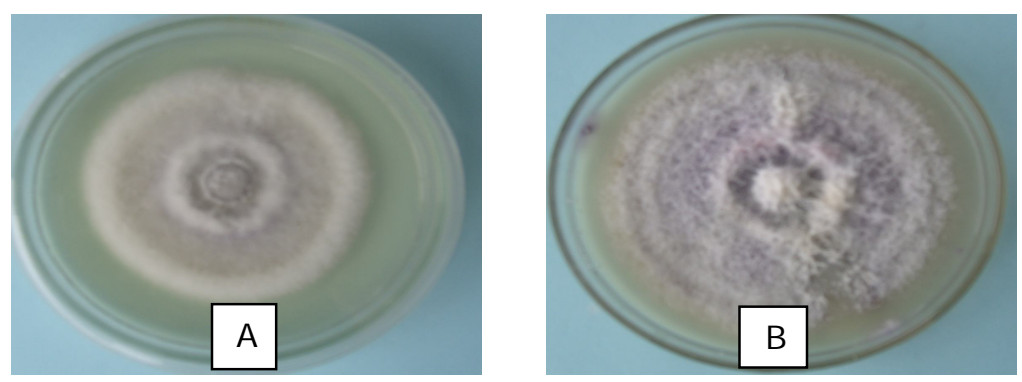

Photograph 1. Isolate of F. oxysporum f. sp. melongenae, (A) 6 days old and (B) 9 days old

Antagonistic effect of Trichoderma asperellum CP (IPM 33) in-vitro against F. oxysporum f. sp. melongenae

The antagonist T. asperellum CP (IPM 33) was tested against $F$. oxysporum $\mathrm{f}$. sp. melongenae on PDA in dual culture method. T. asperellum CP (IPM 33) caused 100\% growth inhibition of F. oxysporum f. sp. melongenae (Photograph 2).

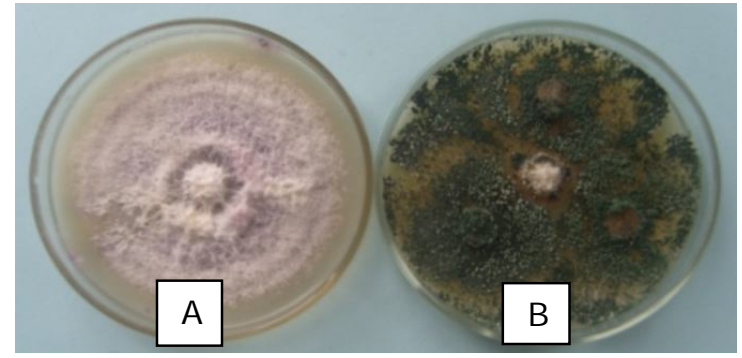

Photograph 2. Antagonistic effect of Trichoderma asperellum CP (IPM 33) in- vitro against F. oxysporum f. sp. melongenae A: Growth of F. oxysporum f. sp. melongenae in absence of antagonist, B: Growth of F. oxysporum f. sp. melongenae in presence of antagonist 
Pathogenicity test of F. oxysporum f. sp. who reported wilting in eggplants in Turkey by F. melongenae oxysporum f. sp. melongenae.

The eggplants were inoculated with inocula of $\mathrm{F}$. oxysporum f. sp. melongenae by soil drenching method to test the capability of the fungus producing disease symptoms in eggplants. The inoculated plant showed typical wilting symptoms. The result is supported by the findings of Begum (2007) who observed that F. oxysporum f. sp. lycopersici was able to produce wilting symptoms in tomato plants. The finding is also supported by the finding of Altinok (2005)

At flowering stage, eggplant var. BAU Begun 2 and Dohazari G inoculated with F. oxysporum f. sp. melongenae isolates showed typical wilting symptoms ranging from drooping of leaves to completely wilting (Photograph 3: A-F) but BAU Begun 1 did not show any symptom (Photograph 3: G). At fruiting stage, eggplant var. BAU Begun 1, BAU Begun 2 and Dohazari G inoculated with F. oxysporum $\mathrm{f}$. sp. melongenae isolates did not show any symptom even in control plots.
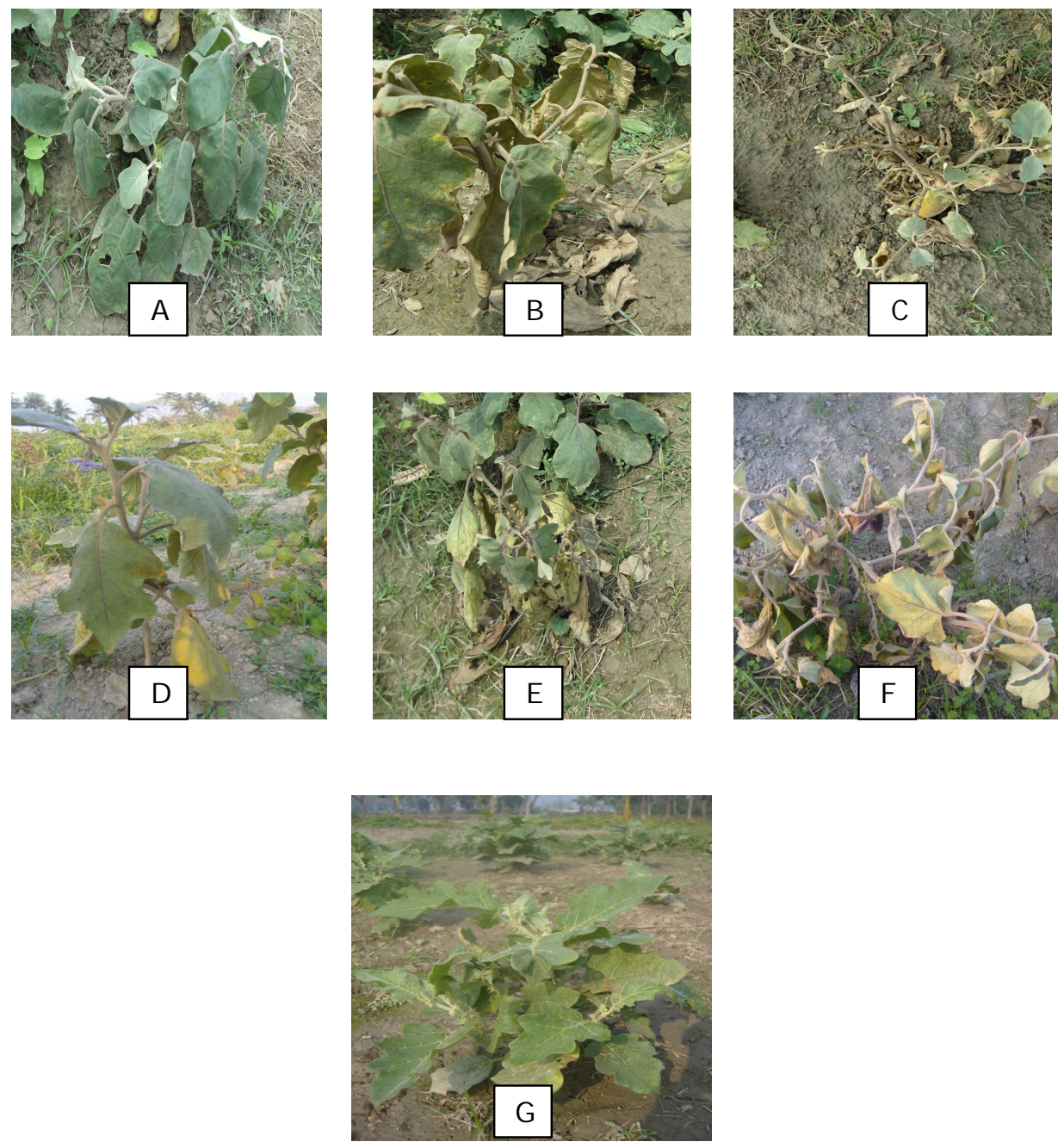

Photograph 3. Development of fusarium wilt symptoms on the inoculated eggplants at flowering stage in the field, A: Drooping of leaves in BAU Begun 2, B: Yellowing of lower leaves in BAU Begun 2, C: Completely wilting in BAU Begun 2, D: Drooping of leaves in Dohazari G, E: Yellowing of lower leaves in Dohazari G, F: Completely wilting in Dohazari G, G: No wilting in BAU Begun 1

\section{Varietal reactions of eggplant against fusarium wilt}

The incidence and severity of the disease varied from 0.00 to 17.04 and 0.00 to $1.21 \%$, respectively. The eggplant varieties BAU Begun 2 and Dohazari G had 12.09 and $17.04 \%$ wilted leaves, respectively.
Variation in the prevalence of fusarium wilt disease incidence and severity recorded in the present study is consistence with the observation of other workers (Rahman and Haque, 1986; Hossain et al., 1991). 


\section{Effect of time of inoculation and treatment}

The incidence was reduced greatly when the treatments were applied before inoculation of pathogen (Table 1). The percentage of recovery of wilted leaves was greatly enhanced up to $83.33 \%$ when the treatments were incorporated to plants by pre-inoculation application (Table 1). The incidence and severity of fusarium wilt disease varied due to variation of different inoculation and treatment application time. Pre-inoculation application of Trichoderma suspension showed the lowest percent leaves wilting as compared to post inoculation application. This result is supported by Begum (2007) who worked with fusarial wilting of tomato. This may be due to the extensive colonization of rhizosphere soil by Trichoderma prior to $F$. oxysporum f. sp. melongenae colonization. On the other hand, in post-inoculation application of Trichoderma suspension, some parts of the rhizosphere soil might already be colonized by the $F$. oxysporum $f$. sp. melongenae prior to Trichoderma colonization released from IPM Lab Trichoderma suspension (Begum, 2007).

Table 1. Effect of time of inoculation and treatment.

\begin{tabular}{llll}
\hline Time of treatment application & Number of Leaves plant ${ }^{-1}$ & \% Leaves Exhibited Wilting & \% Leaves Recovered \\
\hline Pre-inoculation application & 33.36 & $1.50 \mathrm{c}$ & $83.33 \mathrm{a}$ \\
Post-inoculation application & 39.67 & $12.54 \mathrm{~b}$ & $20.70 \mathrm{~b}$ \\
Control & 36.24 & $38.27 \mathrm{a}$ & $0.00 \mathrm{c}$ \\
\hline LSD $(\leq$ 0.05) & & 1.32 & 0.26 \\
\hline
\end{tabular}

Effect of doses of Trichoderma suspension against fusarium wilt of eggplant

The disease incidence was lower when the dose of Trichoderma suspension was $40 \mathrm{ml}^{\text {plant }}{ }^{-1}$ as against $20 \mathrm{ml}^{\text {plant }}{ }^{-1}$ (Table 2). There was no recovery of wilted leaves in case of control plots. The capability of recovering wilted leaves was considerably higher (85.47\%) when the dose of Trichoderma suspension was $40 \mathrm{ml}^{-1 a n t^{-1}}$ and that of $16.58 \%$ in case of $20 \mathrm{ml}^{\text {plant }}{ }^{-1}$. (Table 2) The incidence and severity of fusarium wilt disease significantly varied with the variation of doses of Trichoderma suspension. Application of
Trichoderma suspension reduced the growth rate of $\mathrm{F}$. oxysporum. The findings are in agreement with that of Sivan and Chet (1989) who reported T. harzianum to reduce the chlamydospore germination rate of F. oxysporum. The present study revealed that the application of $40 \mathrm{ml}$ per plant Trichoderma suspension showed the less percent wilting of eggplants as compared to 20 $\mathrm{ml}$, which is supported by the work of Nabi et al. (2009) who applied IPM Lab biopesticide in controlling collar rot of eggplant, tomato and Indian spinach.

Table 2. Effect of time of inoculation and treatment.

\begin{tabular}{lccl}
\hline Time of treatment application & Number of Leaves plant ${ }^{-1}$ & \% Leaves Exhibited Wilting & \% Leaves Recovered \\
\hline Pre-inoculation application & 33.36 & $1.50 \mathrm{c}$ & $83.33 \mathrm{a}$ \\
Post-inoculation application & 39.67 & $12.54 \mathrm{~b}$ & $20.70 \mathrm{~b}$ \\
Control & 36.24 & $38.27 \mathrm{a}$ & $0.00 \mathrm{c}$ \\
\hline LSD $(\leq$ o.05) & & 1.32 & 0.26
\end{tabular}

Effect of growth stages of eggplant for the development of fusarium wilt

The higher percentage of wilted leaves was recorded at flowering stage of eggplant whereas no wilting of leaves was recorded at fruiting stage (Table 3). The wilted leaves had the capability of recovery only at flowering stage and it was $26.47 \%$ of fusarium wilts disease at the fruiting stage whereas that occurred lower at flowering stage of eggplant. The result of the present investigation is supported by the findings of Nabi et al. (2009) who studied the efficacy of Trichoderma suspension in promoting both vegetative and reproductive growth of tomato, chili and Indian spinach and in reducing incidence and severity of wilt disease.

Table 3. Effect of growth stages of eggplant for the development of fusarium wilt.

\begin{tabular}{llll}
\hline Growth stage of eggplant & Number of Leaves plant ${ }^{-1}$ & \% Leaves Exhibited Wilting & \% Leaves Recovered \\
\hline Flowering stage & 36.42 & $7.52 \mathrm{a}$ & $26.47 \mathrm{a}$ \\
Fruiting stage & 47.50 & $0.00 \mathrm{~b}$ & $0.00 \mathrm{~b}$ \\
\hline LSD ( $\leq$ 0.05) & & 0.53 & 0.31 \\
\hline
\end{tabular}


Interaction of eggplant varieties, crop growth stage, dose of Trichoderma suspension and application time on the severity of wilt and recovery of infection

In eggplant var. BAU Begun -1, no infection was observed for any single or combination of treatments. In the varieties BAU Begun 2 and Dohazari G, inoculation and treatments at fruiting stage did not produce any infection. In both the varieties BAU Begun 2 and Dohazari G, pre-inoculation application of treatment at flowering stage @ 40 ml plant-1 Trichoderma suspension yielded no infection. Post-inoculation application of treatment @ 20 and 40 ml plant 1 Trichoderma suspension at flowering stage produced $1.76-2.45 \%$ wilting while it resulted in a maximum of $95.24 \%$ recovery of infection.

\section{Conclusion}

The results obtained in the study indicate the efficacy of Trichoderma suspension in suppressing fusarium wilt disease of eggplant. It was better to apply the Trichoderma suspension prior to inoculation of the pathogen. Therefore, Trichoderma suspension should be applied before the appearance of the disease in the field. The results also indicated that the vulnerable stage of eggplant especially for fusarium wilt disease was flowering stage. In this concern, Trichoderma suspension can bring significant result in suppressing the wilt disease if it is applied before flowering stage of eggplant.

Acknowledgements: Financial assistance from USDA research grant (BG-ARS-122) in conducting this research is gratefully acknowledged.

\section{References}

Agrios, G.N. 2006. Plant Pathology. 5th ed. Elsevier Academic Press, Inc., Burlington USA. 922p.

Al-Chaabi, S. and Matrod, L. 2002. Laboratory study to evaluate efficacy of different Trichoderma spp. isolates on some soil borne pathogenic fungi. Directorate of Agriculture Science Research, Douma, P. O. Box 113, Damascus, Syria. Arab J. Plant Prot. 20(2): 77-83.

Altinok, H.H. 2005. First report of fusarium wilt of eggplant caused by Fusarium oxysporum f. sp. melongenae in Turkey. Plant Path. 54: 4.

Ashrafuzzaman, M.H. 1976. Laboratory manual of Plant Pathology. 1st edn. Jaman Manjil, Iqbal Nagar, Khulna, Bangladesh. 97p.

BBS, 2016. Statistical Yearbook of Bangladesh 2016. Bangladesh Bureau of Statistics. Ministry of Planning, Government of the People's Republic of Bangladesh. Dhaka, Bangladesh. 304p.
Begum, H.A. 2007. Studies on the integrated management for tomato wilt complex. Ph.D. Thesis. Department of Plant Pathology. Bangladesh Agricultural University, Mymensingh. 324p.

Brooks, F.T. 1991. Plant Diseases. 2nd ed. Lekhera Printing Press. Delhi. India. 346p.

Elad, Y., Zyleli, Y. and Chet, I. 1986. Biological control of Macrophomina phaseolina (Tassi) Goid by Trichoderma harzianum. Crop Prot. 5(4): 288-292.

Hossain, M.M., Islam, T. and Rahman, S. 1991. A note on the incidence of bacterial wilt of tomato. Bangladesh J . Agric. Sci. 18(2): 291292.

Kapoor, I.J. 1987. Pathological variability in tomato wilt caused by Fusarium and Rhizoctonia. Indian Phytopath. 40(4): 485490.

Liu, S.D. and Baker, R. 1980. Mechanism of biological control in soil suppressive to Rhizoctonia solani. Phytopath. 70: 404-412.

Meah, M.B. 1997. Diseases in Rabi crops under crop diversification program. Report Crop Diversification Program. Department of Agricultural Extension, Khamarbai, Dhaka. $10 \mathrm{p}$.

Nabi, M.N., Meah, M.B., Ali, M.A. and Hasan, M.M. 2009. Efficacy of IPM lab biopesticide in controlling collar rot of eggplant, Indian spinach, tomato and sunflower. Bangladesh J. Crop Sci. 20(2): 257-264.

Papavizas, G.C. and Lewis, J.A. 1981. Introduction and augmentation of microbial antagonists for the control of soil-borne plant pathogens. pp. 305-322. In: Biological control in crop production. Eds. Papavizas, G.C. BARC symposium 5. Allanheld and Osmun, Totowa NJ.

Rahman, M.A. and Haque, M.O. 1986. Screening of tomato varieties/lines against bacterial wilt. Bangladesh J. Plant Path. 2(1): 15-18.

Sivan, A. and Chet, I. 1989. The possible role of competition between Trichoderma harzianum and Fusarium oxysporum on rhizosphere colonization. Phytopath. 79 (2): 198-203.

Tverdyukov, A.P., Nikonov, P.V. and Yushchenko, N.P. 1994. Trichoderma. Rev. Plant Path. 73(4): 237.

Ullah, C. 2010. Composting municipal solid waste by Trichoderma and its assessment for growth promotion and disease suppression of Capsicum. M.S. Thesis. Department of Plant Pathology. Bangladesh Agricultural University, Mymensingh. 115p.

Wells, H.D., Bell, D.K. and Jaworski, C.A. 1972. Efficacy of Trichoderma harzianum as a biological control for Sclerotium rolfsii. Phytopath. 62: 442-447. 